\title{
Gesture-Based Applications for Elderly People
}

\author{
Weiqin Chen \\ Department of Computer Science, Oslo and Akershus University College of Applied Sciences, \\ Postboks 4 St. Olavs plass 0130 Oslo, Norway \\ Weiqin.Chen@hioa.no
}

\begin{abstract}
According to the literature, normal ageing is associated with a decline in sensory, perceptual, motor and cognitive abilities. When designing applications for elderly people, it is crucial to take into consideration the decline in functions. For this purpose, gesture-based applications that allow for direct manipulations can be useful, as they provide natural and intuitive interactions. This paper examines gesture-based applications for the elderly and studies that have investigated these applications, and it identifies opportunities and challenges in designing such applications.
\end{abstract}

Keywords: Gesture, elderly, direct manipulation, accessibility.

\section{Introduction}

Many industrialised countries are experiencing a huge demographic change, where the proportion of the elderly population is increasing to unprecedented levels, and this population will continue to grow significantly in the future. It is widely accepted that more research is needed to address this issue. With information technologies becoming commonplace in society, the opportunity and necessity for elderly people to access these technologies in their everyday activities have been increasing. Humancomputer interaction must be designed and implemented so that age-related challenges in functional ability, such as perceptual, cognitive and motor functions, are taken into account.

In the last decade, much attention has been devoted to understanding and accommodating the needs of the elderly with respect to interaction with computers through a keyboard and mouse. Recent years have seen the increasing popularity of gesture-based applications, where users use the movements of the hands, figures, head, face and other parts of the body to interact with virtual objects. Furthermore, studies have been carried out to investigate how older users use gesture inputs in their interactions with information technologies. Compared with mouse and keyboard inputs, gesture interfaces have the advantage of simplicity; they require less learning time. For older users, who may operate a mouse or keyboard with limited speed and accuracy, the gesture interfaces can be attractive and make applications more accessible. In this paper, we survey and characterise existing research on gesturebased applications for the elderly and identify the challenges and discuss the research opportunities that those challenges offer. 


\section{Gesture Interfaces}

The input methods used for human-computer interaction are important because the usability of an input method affects the overall effectiveness of an interactive system. A gesture is non-verbal communication made with the hand, finger, head, face or other part of the body. Gestures, independently or in combination with verbal communication, are used commonly to communicate messages. With gestures, humans can directly interact with machines without the extra layer of mechanical devices, such as a mouse or keyboard. This type of interaction is considered more natural and intuitive because humans learn to use gestures from childhood.

Earlier work in gesture interfaces focused on the use of gestures for editing purposes[1]. These interfaces usually involved the user writing directly on the surface of a display with a stylus. The further development of gesture interfaces includes using gloves with sensors to identify hand and finger movements [2], using special suits with sensors to track full body movements [3], finger gestures on a single touch screen and multi-touch tabletops (e.g. Microsoft Surface, Apple touchpad), using an accelerometer to track movements (e.g. Wii remote, $[4,5])$ as well as face recognition and motion tracking with no sensors on the body or controller in the hands (e.g. Sony EyeToy, Microsoft Kinect, Flutter and GestureTek).

Summarising the different types of gesture interfaces and technical approaches, Karam and Schraefel [6] proposed a taxonomy of gestures in human-computer interaction. They categorised the gestures in terms of four key elements: gesture styles, the application domains to which they are applied, input technologies and output technologies used for implementation. Bhuiyan and Picking [7] reviewed the history of gesture controlled user interfaces including types of gestures, their users, applications, technology and the issues addressed over the past 30 years, and they identified trends in technology, application and usability. In their paper, Bhuiyan and Picking [7] also provided a research background for gesture interfaces for elderly or disabled people.

\section{Characteristics of Elderly People}

Age is a surrogate variable that only loosely predicts the amount of disablement of any particular older person [8]. There are many older people who can and do use applications designed for younger users, but it is clear that learning and using fullfeatured applications designed for younger people is very difficult for many older people. The literature has shown that normal ageing is associated with a decline in sensory, perceptual, motor and cognitive abilities. The older users that this paper focuses on are those who suffer from these negative effects of ageing and experience declines in different abilities.

Physical Characteristics. The effects of ageing on motor abilities generally include slower response times, coordination reduction and a loss of flexibility [9]. A decline in motor abilities, especially fine motor skills, is a problem for many older people 
when using mobile phones or laptop computers with integrated mice. Using a computer mouse can be difficult for older users because it requires good hand-eye coordination [10]. Some older users find the double-click very difficult, if not impossible. Reduced motor skills also cause more errors during fine movements, especially when other cognitive functions are required at the same time [11]. Elderly people often confuse the right-click with the left-click while they are at the same time trying to attend to the computer screen.

Visual perception worsens with ageing. The size of the visual field decreases, which leads to a loss of, for example, peripheral vision, colour vision, contrast detection and dark adaptation [12]. In addition, hearing ability declines to $75 \%$ for people between 75 and 79 years of age $[12,13]$. Elderly people also become more easily distracted by details or noises. They have difficulty maintaining attention on more than one aspect at once [14]. Ageing also causes the short-term memory to retain fewer items, the working memory to be less efficient and the perspective memory, that is, the ability to remember, to be reduced when complex tasks are involved [15]. The combination of reduced vision, hearing, memory and mobility contributes to a loss of confidence, which may cause isolation and depression and lead to difficulty in learning, and sometimes hinder the use of new technologies.

Emotion Aspects and Social Engagement. It is often claimed that elderly people are reluctant to make use of state-of-the-art technology, even if they have enough cognitive and physical abilities to do so. Technologies tend to make them uncomfortable. They do not seem to trust their own capabilities and are often afraid of making mistakes that they think may cause damage to the system. This computer anxiety can be reduced after one is taught computer-based skills [16] and when the applications have a higher learnability and a higher recognisability.

Elderly people often experience social isolation. Studies have shown that social disconnectedness (e.g. small social network, infrequent participation in social activities) and perceived isolation (e.g. loneliness, perceived lack of social support) have distinct associations with physical and mental health among older adults [17]. Hence, social activities and engagement are found to be important for the well-being of elderly people.

\section{Research on Gesture-Based Applications for the Elderly}

Gesture interfaces may make applications more attractive and friendly to older users because they are natural and intuitive, they require minimal learning time and they lead to a high degree of user satisfaction. The touch screen has been suggested as a suitable input device for elderly users because it is easy to learn and operate $[18,19]$. There is a large body of work on single finger touch screen applications for older users, but relatively little work has been done on the use of multi-touch, hand, face and body gestures for interacting with applications. In this section, we categories existing research on gesture interface applications for elderly people based on their purposes, including training and rehabilitation, entertainment and social activities, and independent living. 
Training and Rehabilitation. Gesture-based applications can be used for the training and rehabilitation of specific body parts. In such applications, gesture interfaces are usually combined with simulation or virtual reality [20]. The user's gestures are translated into the movements of an avatar in the virtual world. For example, when an older user moves his/her arms, he/she can see in the virtual world the avatar doing the same movements in real-time. Such interfaces are especially useful for elderly users who need to rehabilitate specific body parts. They can guide the users through clinician-prescribed interactive rehabilitation exercises, games and activities that can target these body parts.

A number of multi-touch tabletop applications targeting elderly users have been developed for training purposes. In the HERMES ('Cognitive care and guidance for active aging') project, several cognitive training games were implemented on multitouch tables [21]. Apted et al. [22] and Al Mahmud et al. [23] proposed a list of design guidelines for tabletop-based applications for the elderly. Following these guidelines, Annett et al. [24] developed a suite of five motor-based rehabilitation activities for older users. For an overview of multi-touch tabletop applications for training and rehabilitation for the elderly, see [25].

Entertainment and Social Activities. Due to the decline in abilities that comes with ageing, elderly people tend to live an isolated existence. Therefore, the social isolation of the elderly is becoming a pressing problem. To improve their quality of life, it is essential that elderly people have an active social and physical life, which is often called 'active ageing'[26]. An increasing number of multi-touch tabletop applications promote entertainment and social interactions among elderly people. Hollinworth and Hwang [27] designed an e-mail application on a multi-touch table for elderly users, allowing the user to use finger gestures to manipulate objects on the table. 'Familiarity' as a design principle was adopted in the design of the interface, where tools were provided in the form of familiar visual objects and manipulated by finger gestures, just like their real-world counterparts, rather than with buttons, icons and menus. The formative evaluation showed that three of the four participants were able to carry out some of the basic e-mail tasks with no prior training and little or no help. Sharetouch [28] is another multi-touch tabletop application designed to enable social interaction among the elderly living in a community. For an overview of multi-touch tabletop applications for social interactions among the elderly, see [25].

Several Nintendo Wii games, especially sport games such as Bowling, have also been used in residential homes [29-31] to promote social and physical activities amongst elderly people. Some research has shown the positive effects of Wii games on elderly people's physical health [32] and mental well-being [32, 33]. Voida and Greenberg [30] reported the results of their qualitative study on Wii games serving as a meeting place for diverse people. Their study participants were the residents of a retirement community, who played the Wii Bowling game. An interesting finding from this study was that a more experience elderly player advised the other players to bowl with the Wii remote held upside down, so that they would only see the one relevant button. The Wii remote has many buttons which are not needed to play this game, but they interrupt the normal sequence by opening up menus when accidentally 
pressed. This was unexpected for the older players, and when these menus would pop up, they were afraid that they had destroyed the game. To prevent the elderly players from accidently pressing the irrelevant buttons, Neufeldt [29] covered these buttons in his study.

Neufeldt [29] conducted his study with members of a fitness programme in a retirement home. Six participants played four rounds of Wii Bowling with each round associated with a regular fitness session that occurred once a month. Observation was the main data collection method. In addition to the irrelevant button on the Wii remote, this study found that the game required a high level of attention from the elderly players, because the button must be released at the right moment, and this requires good hand-eye coordination. The explanations and help from the researchers, the hints from other elderly players and the sounds of the game caused considerable stress for the participants, which resulted in less fun and more reluctance to play. The researcher, however, observed development in the capabilities of the elderly participants from round to round, which indicated that Wii games could help improve coordination capabilities and encourage the elderly to move their arms.

Harley et al. [31] conducted a longitudinal study of older people's use of the Wii in Shelter Housing over a period of one year. Data were collected using observations, interviews and video recording. Through interaction analysis, the study highlighted how older people actively constructed the sense of a meeting place by gaining control over the space and engaging in the social processes. Harley et al. [31] concluded their paper by presenting five design implications and guidelines for encouraging appropriation and empowerment among older people through game play in communal housing settings.

Jung et al. [32] conducted a six-week comparative study to examine the impact of playing Wii games on the psychological and physical well-being of the elderly in a long-term care facility. The experiment group included 45 residents who played Wii games; the control group played traditional board games. The results showed that playing Wii games had a positive impact on the overall well-being of the elderly compared to the control group.

Gerling et al. [34] conducted two studies using Microsoft Kinect. The first study focused on the suitability of the gesture set for institutionalised older people. The gesture set included four static body gestures and four dynamic body gestures. Seventeen elderly people from 60 to 90 years of age participated in the study. The second study focused on testing a game using body gestures. Twelve elderly people from 60 to 91 years of age participated in the study. Both qualitative data (questionnaire and observation) and quantitative data (performance metrics) were collected. Gerling et al. [34] concluded the paper by presenting seven guidelines for full-body interactions in games for elderly people.

Independent Living. It is commonly recognised that elderly people can benefit from the use of information and communication technologies in their homes to allow for longer independent living. However, in order to enable the independent living of elderly people, many challenges need to be addressed [35]. Various assistive technologies and services have been developed to support independent living in 
different aspects of life, including safety, health and wellness and social connectedness [36]. However, few systems have taken advantage of gesture technology. As a part of IBM's accessibilityWorks project, a gesture interface called TouchFree Switch [37] was developed for older users, allowing the user to interact with the Mozilla web browser by the tip of the head, a shrug of the shoulder, a finger movement or any other body movement. Furthermore, the TouchFree Switch interface allows users to choose their own gestures and associate them with tasks. Jia et al. [38] developed a hands-free intelligent wheelchair control with head gestures for the elderly and people with disabilities. The recognised head gestures are used to generate motion control commands to the motion controller in the wheelchair so that it can control the motion of the wheelchair according to the user's intentions. The preliminary results showed that the gesture interface was very useful for the users who have restricted limb movements.

The Gesture Pendant [39] is a wearable device allowing older users to control home automation systems via hand gestures. Thus, home devices to control, for example, entertainment equipment and room lighting can be controlled by hand movements. Eight standard hand gestures ('horizontal pointed finger up', 'horizontal pointed finger down', 'vertical pointed finger left', 'vertical pointed finger right', 'horizontal flat hand down', 'horizontal flat hand up', 'open palm hand up' and 'open palm hand down') were defined as control gestures. In addition, the system allowed the users to self-define gestures for the tasks, for example, 'fire on', 'fire off', 'door open', 'door close', 'window up', and 'window down'.

Open Gesture [40] allows older people to use hand gestures to perform a diverse range of tasks at home via a television interface. After running the application (which could be initiated by selecting a pre-configured television channel), the user could see his/her image on the television screen, which was filmed through a connected webcam. The user could point at different objects using hand gestures to perform various tasks, such as making a telephone call, playing 'brain training' games, controlling the computer or home environment and social networking.

\section{$5 \quad$ Challenges and Opportunities}

Gesture interfaces provide realistic and affordable opportunities and offer some potential for improving the independence and quality of life of elderly people. However, there remain significant challenges to overcome.

Technological Challenges. Due to the anxiety that elderly users experience when interacting with technologies, gesture-based applications must provide reliable and easily performable gestures. Gesture recognition is a challenging task and essential for gesture interfaces. Techniques such as hidden Markov models (HMMs), particle filtering and condensation, finite-state machine (FSM) and artificial neural networks (ANNs) have been adopted for recognising hand and arm gestures [41, 42]. Moreover, 
new and improved tools and techniques must be at the centre of research in order to increase the reliability and accuracy of gesture recognition systems. Many gesturebased applications have been developed for user groups besides the elderly and have proved useful to these user groups. For example, Stomp [43] is an application designed to support social and physical interactions for people with intellectual disability. The mini-games in this application can be easily adapted for elderly people in communities or residential homes. A gesture-based application should be able to lower the resistance of the users and offer a clear benefit, whether physical, medical or emotional, in order for elderly users to accept it. This must be achieved on several levels. On the design level, the application must be adapted to older users' physical and perceptual characteristics. The interface should offer a certain degree of familiarity to overcome reservations. On the function level, the benefit of using the application must be appreciable in order to provide a motivation for its use. A balance must be established between intuitive use and practical learning.

Methodological Challenges. The results from earlier studies have shown that there is a wide gap between the young designers' personal experience and the experiences of the older users. In order to design and implement useful and accessible applications for elderly people, it is important to increase the awareness of the characteristics of elderly people among the designers and developers of the applications. Thus, a usercentred approach should be adopted in the design and development process. Designers cannot only follow guidelines; they must also involve older users from the early stage of the development process. Due to the gap in experience, those designing for older users will remain dependent on testing with a range of older users in order to verify the assumptions made in their designs. However, older people provide far greater challenges to user-centred design than more traditional user groups [44]. Newell [44] proposed different methodologies for involving older adults in the design process, including the use of theatre. The studies on elderly people with gesture-based applications have focused mainly on attitudes and subjective evaluation. Owing to the inherent limitation of subjective measurements, it is important to use objective measures, such as performance data. Although previous research has suggested that gesture interfaces may be especially easy for older users to use, as they allow for direct manipulation, until now, few researchers have systematically investigated the usability of gesture-based applications for older users. Hence, systematic studies are necessary to understand how elderly people use these applications and to establish design recommendations for such applications.

In order to confirm whether gesture interfaces are acceptable for actual use, longterm investigation following the adoption of the technology is important. Longitudinal studies should focus on the usability of gesture interfaces, the acceptance of gesture interfaces by elderly users including attributes and motivations as well as their performance and improvement in sensory, perceptual, motor and cognitive abilities. 


\section{Conclusion}

Information and communication technologies (ICT) have been proposed as useful for offsetting the negative effects of physical, cognitive and social ageing. However, the uptake of ICT by elder people is rather low. Innovative interaction technologies, such as gesture technology, have great potential for improving the accessibility of interactive systems to elderly users. Despite the limited research, the evidence suggests that gesture technology is an applicable and practical technology for this user group. However, we still need to understand how to take advantage of this technology to provide the best possible support for elderly people. Future projects could pursue enquiry in many directions in order to fully explore the potential of gesture technology.

\section{References}

1. Rhyne, J.: Dialogue Management for Gestural Interfaces. ACM SIGGRAPH Computer Graphics 21, 137-142 (1987)

2. Zimmerman, T.G., Lanier, J., Blanchard, C., Bryson, S., Harvill, Y.: A hand gesture interface device. SIGCHI Bull. 18, 189-192 (1986)

3. Fitzgerald, D., Foody, J., Kelly, D., Ward, T., Markham, C., McDonald, J., Caulfield, B.: Development of a wearable motion capture suit and virtual reality biofeedback system for the instruction and analysis of sports rehabilitation exercises. In: Proc. of IEEE Conf. Eng. Med. Biol. Soc., pp. 4870-4874. IEEE (2007)

4. Sawada, H., Hashimoto, S.: Gesture Recognition Using an Accelerometer Sensor and its Application to Musical Performance Control. Electronics and Communications in Japan Part 3, 9-17 (2000)

5. Amini, N., Sarrafzadeh, M., Vahdatpour, A., Xu, W.: Accelerometer-based on-body sensor localization for health and medical monitoring applications. Pervasive Mob. Comput. 7, 746-760 (2011)

6. Karam, M., Schraefel, M.C.: A taxonomy of gestures in human computer interactions. Technical report, Electronics and Computer Science, University of Southampton (2005)

7. Bhuiyan, M., Picking, R.: Gesture Control User Interface, what have we done and what's next? In: Bleimann, G.U., Doland, S.P., Furnell, M.S., Grout, V. (eds.) Proceedings of the Fifth Collaborative Research Symposium on Security, E-learning, Internet and Networking (SEIN-2009), pp. 59-68. University of Plymouth, Darmstadt (2009)

8. Hawthorn, D.: How universal is good design for older users? ACM SIGCAPH Computers and the Physically Handicapped, 38-45 (2002)

9. Rogers, W.A., Fisk, A.D., Mead, S.E., Walker, N., Cabrera, E.F.: Training older adults to use automatic teller machines. Hum. Factors 38, 425-433 (1996)

10. Walker, N., Philbin, D.A., Fisk, A.D.: Age-related differences in movement control: adjusting submovement structure to optimize performance. J. Gerontol. B Psychol. Sci. Soc. Sci. 52, 40-52 (1997)

11. Charness, N., Bosman, E.A.: Human factors and design for older adults. In: Birren, J.E., Schaie, K.W. (eds.) Handbook of the Psychology of Aging, pp. 446-463. Academic Press, New York (1990)

12. Fozard, J.L.: Vision and hearing in aging. In: Birren, J.E., Schaie, K.W. (eds.) Handbook of the Psychology of Aging, pp. 150-170. Academic Press, New York (1990) 
13. Schieber, F.: Aging and the senses. In: Birren, J.E., Sloan, R., Cohen, G. (eds.) Handbook of Mental Health and Aging, pp. 251-306. Academic Press, New York (1992)

14. McDowd, J.M., Craik, F.I.: Effects of aging and task difficulty on divided attention performance. J. Exp. Psychol. Hum. Percept. Perform. 14, 267-280 (1988)

15. Craik, F.I.M., Jennings, J.J.: Human memory. In: Craik, F.I.M., Salthouse, T.A. (eds.) Handbook of Aging and Cognition, pp. 51-110. Erlbaum, Hillsdale (1992)

16. Ellis, D., Allaire, J.C.: Modeling computer interest in older adults: the role of age, education, computer knowledge, and computer anxiety. Hum. Factors 41, 345-355 (1999)

17. Cornwell, E.Y., Waite, L.J.: Social Disconnectedness, Perceived Isolation, and Health among Older Adults. J. Health Soc. Behav. 50, 31-48 (2009)

18. Yarnold, P.R., Stewart, M.J., Stille, F.C., Martin, G.J.: Assessing functional status of elderly adults via microcomputer. Percept. Mot. Skills 8, 689-690 (1996)

19. Tobias, C.L.: Computers and the Elderly: A Review of the Literature and Directions for Future Research. In: Proc. of the Human Factors Society 31st Annual Meeting, pp. 866-870. Human Factors Society, Santa Monica (1987)

20. Kallio, S., Kela, J., Mäntyjärvi, J., Plomp, J.: Visualization of Hand Gestures for Pervasive Computing Environments. In: Proceedings of the Working Conference on Advanced Visual Interfaces (AVI 2006), pp. 480-483. ACM, New York (2006)

21. Facal, D., Buiza, C., González, M.F., Soldatos, J., Petsatodis, T., Talantzis, F., Urdaneta, E., Martínez, V., Yanguas, J.J.: Cognitive Games for Healthy Elderly People in a Multitouch Screen. In: Proc. of the International IDRT4ALL, Barcelona, Spain (2009)

22. Apted, T., Kay, J., Quigley, A.: Tabletop Sharing of Digital Photographs for the Elderly. In: Proc. of CHI 2006, pp. 781-790 (2006)

23. Al Mahmud, A., Mubin, O., Shahid, S., Martens, J.: Designing and Evaluating the Tabletop Game Experience for Senior Citizens. In: Proc. of NordiCHI 2008, pp. 403-406 (2008)

24. Annett, M., Anderson, F., Goertzen, D., Halton, J., Ranson, Q., Bischof, W.F., Boulanger, P.: Using a multi-touch tabletop for upper extremity motor rehabilitation. In: Proc. of the 21st Annual Conference of the Australian Computer-Human Interaction Special Interest Group: Design, pp. 261-264. ACM, New York (2009)

25. Loureiro, B., Rodrigues, R.: Multi-Touch as Natural User Interface for Elders: A survey. In: Proc. of 6th Iberian Conference on Information Systems and Technologies CISTI 2011, Chaves, Portugal, pp. 573-578 (2011)

26. OECD: Reforms for an Ageing Society. OECD Publishing, Paris (2000)

27. Hollinworth, N., Hwang, F.: Investigating familiar interactions to help older adults learn computer applications more easily. In: Proceedings of the 25th BCS Conference on Human-Computer Interaction (BCS-HCI 2011), pp. 473-478. British Computer Society, Swinton (2011)

28. Tsai, T.-H., Chang, H.-T., Chang, Y.-M., Huang, G.-S.: Sharetouch: A system to enrich social network experiences for the elderly. J. Syst. Softw. 85, 1363-1369 (2012)

29. Neufeldt, C.: Wii play with elderly people. International Reports on Socio-Informatics (IRSI) 6 (2009)

30. Voida, A., Greenberg, S.: Wii all play: the console game as a computational meeting place. In: Proc. of the SIGCHI Conference on Human Factors in Computing Systems (CHI 2009), pp. 1559-1568. ACM, New York (2009)

31. Harley, D., Fitzpatrick, G., Axelrod, L., White, G., McAllister, G.: Making the Wii at home: game play by older people in sheltered housing. In: Leitner, G., Hitz, M., Holzinger, A. (eds.) USAB 2010. LNCS, vol. 6389, pp. 156-176. Springer, Heidelberg (2010) 
32. Jung, Y., Li, K.J., Janissa, N.S., Gladys, W.L.C., Lee, K.M.: Games for a better life: effects of playing Wii games on the well-being of seniors in a long-term care facility. In: Proc. of the Sixth Australasian Conference on Interactive Entertainment (IE 2009). ACM, New York (2009)

33. Theng, Y.-L., Chua, P.H., Pham, T.P.: Wii as entertainment and socialisation aids for mental and social health of the elderly. In: Proc. CHI 2012 Extended Abstracts on Human Factors in Computing Systems (CHI EA 2012), pp. 691-702. ACM, New York (2012)

34. Gerling, K., Livingston, I., Nacke, L., Mandryk, R.: Full-body motion-based game interaction for older adults. In: Proc. of the SIGCHI Conference on Human Factors in Computing Systems (CHI 2012), pp. 1873-1882. ACM, New York (2012)

35. Edwards, W.K., Grinter, R.E.: At Home with Ubiquitous Computing: Seven Challenges. In: Abowd, G.D., Brumitt, B., Shafer, S. (eds.) UbiComp 2001. LNCS, vol. 2201, pp. 256-272. Springer, Heidelberg (2001)

36. Alwan, M., Wiley, D.: State of Technology in Aging Services. Report, Center for Aging Services Technologies (2007)

37. Hanson, V.L., Brezin, J.P., Crayne, S., Keates, S., Kjeldsen, R., Richards, J.T., Swart, C., Trewin, S.: Improving web accessibility through an enhanced open-source browser. IBM Systems Journal 44, 573-588 (2005)

38. Jia, P., Hu, H., Lu, T., Yuan, K.: Head gesture recognition for hands-free control of an intelligent wheelchair. Journal of Industrial Robot 34, 60-68 (2007)

39. Gandy, M., Starner, T., Auxier, J., Ashbrook, D.: The Gesture Pendant: A Self-illuminating, Wearable, Infrared Computer Vision System for Home Automation Control and Medical Monitoring. In: Proceedings of the 4th IEEE International Symposium on Wearable Computers (ISWC 2000), pp. 87-94. IEEE Computer Society, Washington, DC (2000)

40. Bhuiyan, M., Picking, R.: A Gesture Controlled User Interface for Inclusive Design and Evaluative Study of Its Usability. Journal of Software Engineering and Applications 4, 513-521 (2011)

41. Mitra, S., Acharya, T.: Gesture Recognition: A Survey. IEEE Transactions on Systems, Man and Cybernetics, Part C: Applications and Reviews 37, 311-324 (2007)

42. Khan, R.Z., Ibraheem, N.A.: Survey on Gesture Recognition for Hand Image Postures. International Journal of Computer and Information Science 5, 110-121 (2012)

43. Wyeth, P., Summerville, J., Adkins, B.: Stomp: an interactive platform for people with intellectual disabilities. In: Romão, T., Correia, N., Inami, M., Kato, H., Prada, R., Terada, T., Dias, E., Chambel, T. (eds.) Proceedings of the 8th International Conference on Advances in Computer Entertainment Technology (ACE 2011). ACM, New York (2011)

44. Newell, A.F.: User sensitive design for older and disabled people. In: Helal, S., Mokhatari, M., Abdularazak, B. (eds.) The Engineering Handbook of Smart Technology for Ageing, Disability and Independence: Computer and Engineering for Design and Applications, pp. 787-892. Wiley, New Jersey (2008) 